\title{
Impact of pile foundations adjacent to tunnels in sandy stratum
}

\author{
MONICA MALHOTRA ${ }^{1}$, VAISHALI SAHU ${ }^{1}$, AMIT SRIVASTAVA $^{2}$ \\ and ANIL KUMAR MISRA ${ }^{3, *}$ \\ ${ }^{1}$ Department of Civil and Environmental Engineering, The Northcap University, Gurugram, India \\ ${ }^{2}$ School of Civil Engineering, Lovely Professional University, Jalandhar, India \\ ${ }^{3}$ Department of Geology, School of Physical Sciences, Sikkim University (A Central University), Gangtok, \\ India \\ e-mail: monicamalhotra28@gmail.com; vaishalisahu@ncuindia.edu; dramitsrivastava732@gmail.com; \\ anilgeology@gmail.com
}

MS received 3 May 2018; revised 7 April 2019; accepted 7 June 2019

\begin{abstract}
In recent years, with rapid urbanization and construction of underground pipeline facilities for the transmission of electricity, supply of water, sewage disposal or provision of facilities like telephone lines, gas pipe lines, etc., it is highly probable to encounter an existing pipeline system in the vicinity of a proposed foundation of a structure. Hence, design and construction of new foundation structure near the existing subsurface pipeline system is imperative and should be addressed for keeping either a minimum safe clearance between tunnel/buried pipe and pile without compromising the capacity of pile or estimating the reduced capacity due to existing nearby pipeline or tunnel, which is an important aspect in the analysis and design of pile foundation. Present study demonstrates a model and numerical study of the behaviour of a single pile in the vicinity of existing tunnel/buried pipe in a cohesionless soil. During experimental work, a small scale pile model was tested for its load-settlement behaviour without and with the existence of buried PVC pipe modelled as a tunnel in the vicinity near the shaft. The complete experimental set-up consisted of a steel box filled with sand at two different relative density values and vertical concentric load was applied on the model pile through a hydraulic jack and reaction frame arrangement connected with a proving ring. Results of pile loading test have been provided, which demonstrate the tunnel-pile interaction problem effect on the pile capacity, and it was also numerically verified using commercially available finite-element tool. With due verification, parametric study is performed, through finite-element analysis, by varying the range of input parameters such as unit weight, internal friction angle, diameter of pile and elastic modulus of pile material to the soil modulus ratio. Based on the results of numerical analysis in terms of load-settlement curves, it is noted that there is $15-20 \%$ reduction in the pile capacity of a single pile to be installed in cohesionless soil in the vicinity of the existing buried pipe or tunnel, which depends on the geometries of the pile and tunnel construction, properties of the in situ soil and zones of influence due to relative stiffness of soil and pipe materials.
\end{abstract}

Keywords. Pile foundation; tunnel-pile interaction; load-settlement curve; finite-element analysis.

\section{Introduction}

As the population grows, development of urban areas involve the construction of high rise buildings along with tunnels, and buried conduits for various supplies and transport to address the needs of the future. Therefore, coexistence of buried pipe/tunnel and deep foundation is a common problem. As the space available is limited, it is very common that pile foundation lies in the vicinity of already existing tunnel/buried conduit or tunnelling takes place in the vicinity of already existing substructures, which in turn imposes changes in the load carrying capacity

*For correspondence

Published online: 23 July 2019 of designed pile. Hence, it is necessary to understand how the pile-tunnel interaction affects the pile capacity, which in turn affects the safety and serviceability of pile-supported structures.

Most of the research has shown that sub-surface soil deformation due to tunnelling caused differential settlement in adjacent building supported on shallow foundations whereas in case of pile foundations, subsurface soil deformation has significant impact on the pile response. In the past, tunnel-pile-soil interaction has been analysed in different methods such as (a) analytical method [1, 2], (b) experimental method [3, 4] and (c) numerical method [5, 6].

Many researchers have addressed the issue of pile capacity and settlement due to the construction of new 
tunnel. Pile response due to soil movement can be calculated using analytical equations available, which have been derived using cavity expansion theory [2,7]. The effect of tunnelling on the already existing pile footing depends on distance between pile and tunnel, soil volume loss due to movement during tunnelling, tunnel diameter and pile diameter. Even soil parameters influence the load carrying capacity of end bearing and friction piles $[8,9]$. The analytical solutions are computationally efficient over numerical methods, though assumptions in soil behaviour and soil-structure interaction are required to obtain the results. For example, Winkler-based two-stage analysis methods can be used for pile-tunnel interaction problem [10].

A lot of literature is available on the experimental methods for studying the behaviour of pile due to tunnelling in dry dense sand $[3,4,11]$ and cohesive soil [12]. Centrifuge modelling is considered to be a very useful technique for studying soil-pile-tunnel interaction and capable of recreating the stress conditions arising during full-scale constructions using models of reduced scale and at the same time, it is possible to attain specific soil parameters in a laboratory environment.

The recorded data from centrifuge modelling showing surface settlement during tunnelling as well as settlement of piles due to tunnels at various distances have been used to identify a zone around the tunnel where there is possibility of large settlement.

From the stresses introduced in tunnel lining due to existing pile at $0.7 D, 2.0 D$ and $2.7 D(D=$ diameter of tunnel) distances from tunnel perimeter, it has been noted that stresses are maximum when the pile lies in the close vicinity of tunnel [4]. Results available showed that building stiffness plays a consequential role in reducing the distortion of building due to tunnelling [11].

Studies [13,14] demonstrated the effects of tunnelling on adjacent existing piles using numerical approach. A loss in axial capacity has been observed and results of analysis were compared to experimentally measured results [15-17]. Studies suggest that tunnel excavation leads to relief of stress to the surrounding soil and causes ground movement in vertical and horizontal direction. The vertical movement of supporting soil depends on the stresses, modulus of soil and soil type. The movement of soil in vertical direction is in the downward direction, causing settlement in downward direction. Hence, when a pile lies in the vicinity of tunnel, there is possibility of reduction in load carrying capacity of the pile due to development of negative skin friction on the pile.

To date, sufficient work has been done on the effects of tunnelling process on the already existing piles. When tunnelling takes place adjacent to existing underground structures, it induces bending moments, settlement and lateral deflection in the piles. This is due to volume loss during tunnelling process. The influence of tunnelling can be assessed only if study on ground movement is done accurately.
This tunnel-pile interaction problem also includes the cases when placing of pile foundation takes place adjacent to already existing tunnel. This problem is categorized as effect of piling on tunnel and effect of existing tunnel on pile. Literature is available showing a significant impact of construction and loading of pile or pile group in terms of settlement of tunnel and deflection in tunnel lining. Based on this, guidelines on the minimum distance between new pile foundation and existing tunnel are available. These guidelines are based on the experience, in spite of theoretical understanding of pile - tunnel interaction problem. In order to improve these guidelines, finite-element method (FEM) has been used [18] to study the influence of pile group loading on the existing tunnel. It has provided guidelines regarding clear distance between tunnel and pile. Movements and stress changes are expected during the construction of a pile on buried tunnel $[19,20]$.

Numerical analysis of a circular tunnel in the vicinity of a single pile shaft in a two-dimensional space occupied by uniformly distributed cohesionless soil was performed by the authors [21] and based on the results of the numerical analysis, in terms of load-settlement curves, charts were prepared to estimate the reduction in the frictional capacity of a single pile.

To extend the studies for practical applications, the objectives of the present study are to understand the behaviour of pile adjacent to existing buried tunnel/pipe. The analysis undertaken as part of this work consists of the following:

i. Model study of the load-settlement response of the single pile placed adjacent to tunnel/buried pipe in dry cohesionless sand and its verification through finiteelement-based numerical code using PLAXIS 2D.

ii. Parametric study on estimating the load carrying capacity of single pile placed near the tunnel or buried pipe considering variation in the input parameters and presenting the results in the form of charts.

\section{Experimental set-up}

Experimental set-up for studying the load-settlement behaviour of single pile placed in the vicinity of the existing utility tunnel is shown in figure 1(a). The model consists of a steel box of dimension $600 \mathrm{~mm} \times 600 \mathrm{~mm} \times 600 \mathrm{~mm}$ (sand filled), model piles of diameter 30,34 and $38 \mathrm{~mm}$, PVC pipe of diameter $50 \mathrm{~mm}$ and a loading frame. From dimensional analysis, it is noted that model piles of diameter $30-38 \mathrm{~mm}$ are used, while the tunnel modelled as a PVC pipe has diameter $50 \mathrm{~mm}$, and the $D_{\text {tunnel }} / D_{\text {pile }}$ ratio ranges from 1.67 to 1.31. In real life problem, assuming an average pile diameter of $1.00 \mathrm{~m}$, even the highest ratio examined would correspond to a tunnel with a diameter of $1.67 \mathrm{~m}$, which is small for anything more than a utility tunnel or big pipeline. 
(a)

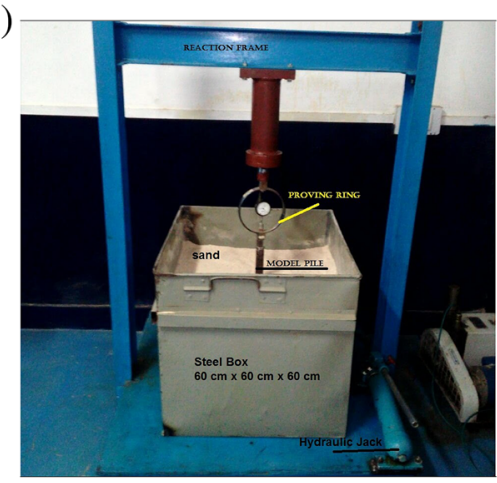

(c)

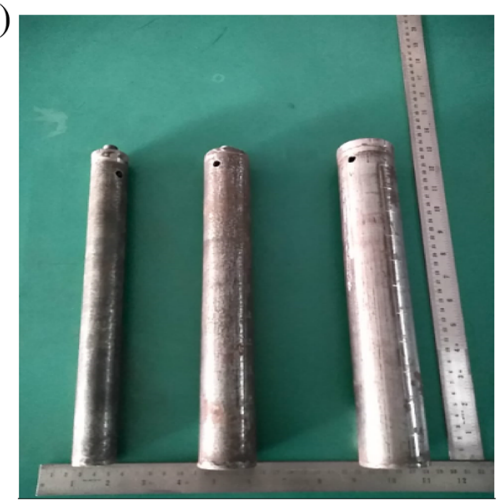

(b)

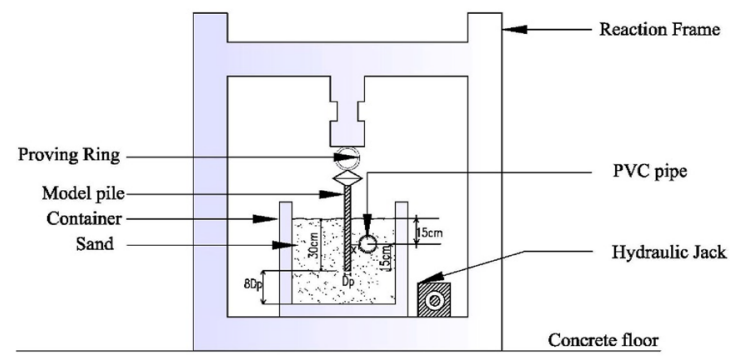

(d)

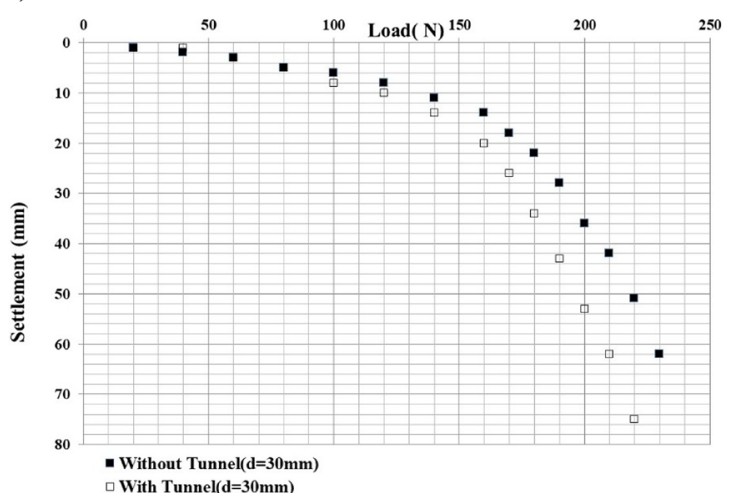

Figure 1. (a) Experimental set-up for the model study. (b) Schematic of the experimental set-up indicating depth, location and size of the utility tunnel. (c) Model pile and PVC pipe used in the experimental program. (d) Load-settlement response with and without tunnel.

This justifies the focus of the present study, i.e., pile capacity examined in the vicnity of the utility tunnel only.

The vertical load was applied on the model pile using a hydraulic jack of 2 tonnes capacity and the same was measured using a proving ring of 2 tonnes capacity. To ensure that there is no interference between the walls of the tank and pile, a vertical clearance of eight times the pile diameter was provided below the pile tip as suggested by Robinsky and Morrison [22]. Bolton [23] suggested performing CPT at least $10 B$ away from any hard boundary; therefore, for $30 \mathrm{~mm}$ pile, $300 \mathrm{~mm}$ distance was maintained from the container wall. Further, as different diameter piles are used in this study, the inside walls of the sand container were polished smooth to reduce friction with the soil.

A schematic layout of the experimental set-up has also been shown in figure 1(b). The model piles used in the present study shown in figure 1(c) and (d) show the typical load-settlement responses of model pile of diameter $30 \mathrm{~mm}$ placed in dry sand without and with the presence of utility tunnel, which clearly indicates that there is a considerable reduction in the capacity of the pile due to the presence of utility tunnel. From the load-settlement curve, for the case analysed, the reduction in pile capacity is $10.86 \%$.
In this study, a series of tests have been carried out to investigate the response of a single pile in the form of loadsettlement curve with and without existing utility tunnel. Tests were performed on loose medium sand (relative density $(\mathrm{RD})=50 \%)$ and very dense sand $(\mathrm{RD}=80 \%)$. The settlement of pile on each load increment was noted from the scale marked on the pile shaft.

\subsection{Sand properties}

Local sand was used having size in the range of $0.15-1.18 \mathrm{~mm}$ as observed from the grain size distribution (figure 2) and tested for the physical properties as per IS2720 (Part4-1985) specifications; numerical values of some important geotechnical properties are tabulated in table 1 . The test was performed at two RD values, i.e., $50 \%$ and $80 \%$.

\subsection{Model pile and tunnel}

A pile has been selected to represent the case of deep, stiff piles extended in cohesionless soil. Piles used in the present 


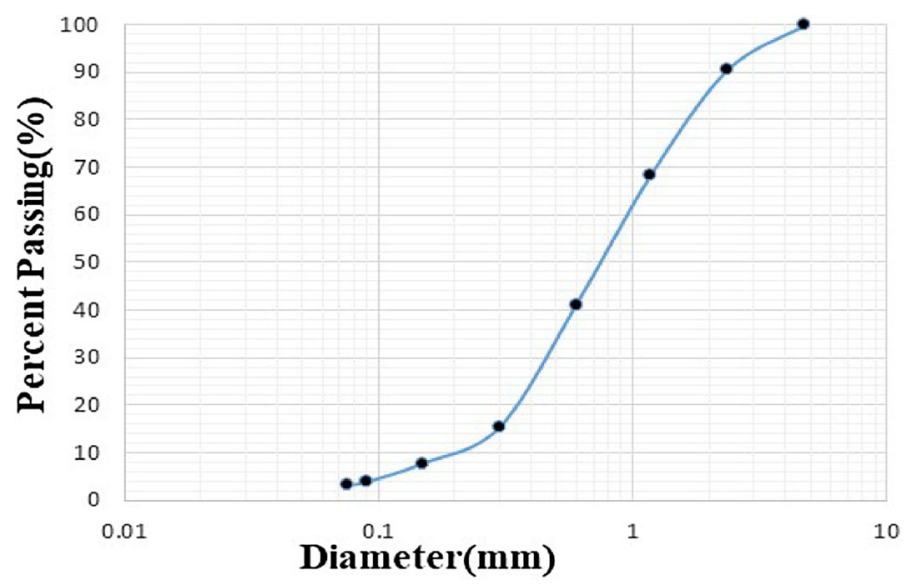

Figure 2. Grain size distribution of dry sand.

study are steel pipes of diameter 30,34 and $38 \mathrm{~mm}$, and $500 \mathrm{~mm}$ total length, plugged at both ends. A $50 \mathrm{~mm}$ diameter $\left(D_{\mathrm{t}}\right)$ PVC pipe as a tunnel is placed at a horizontal distance $X\left(D_{\mathrm{t}}\right)$ from the middle of the pile shaft.

\subsection{Sample preparation and test procedure}

For placing the sand at two different RD values, the calculation was first performed on the amount of dry sand to be utilized. The $e_{\max }$ (maximum void ratio corresponding to minimum density that can be achieved) and $e_{\min }$ (minimum void ratio corresponding to maximum density that can be achieved) values of the sand to be used in the experimental study were obtained through standard experimental procedure detailed in IS 2720-14: Methods of test for soils, Part 14: Determination of density index (RD) of cohesionless soils. Using the equation $R D(\%)=\frac{\left(e_{\max }-e_{\mathrm{n}}\right)}{\left(e_{\max }-e_{\min }\right)} \times 100 \%$, the values of $e_{\mathrm{n}}$ and corresponding dry density $\left(\rho_{\mathrm{d}}\right)$ values are obtained, respectively, as 0.575 and $16.36 \mathrm{kN} / \mathrm{m}^{3}$ for $\mathrm{RD}=50 \%$ and 0.494 and $17.25 \mathrm{kN} / \mathrm{m}^{3}$ for $\mathrm{RD}=80 \%$. As the total volume of the tank to be filled with sand is known in advance, the amounts of dry sand to be used for

Table 1. Physical properties of the local sand.

\begin{tabular}{ll}
\hline Physical properties of local sand & Value \\
\hline Grain size analysis & \\
Effective size $D_{10}$ & 0.21 \\
Coefficient of uniformity $C_{\mathrm{u}}$ & 4.8 \\
Coefficient of curvature $C_{\mathrm{c}}$ & 1.2 \\
Specific $G_{\mathrm{s}}$ & 2.63 \\
Dry unit weights $\left(\mathrm{kN} / \mathrm{m}^{3}\right)$ & \\
Dry unit weight of loose medium sand & 15.12 \\
Dry unit weight of dense sand & 17.87 \\
Void ratio & \\
Maximum void ratio $e_{\max }$ & 0.71 \\
Minimum void ratio $e_{\min }$ & 0.44 \\
\hline
\end{tabular}

achieving 50\% RD and 80\% RD values are calculated in advance and the same amount of sand is used for filling the tank in layers to achieve the required RD. For achieving $50 \% \mathrm{RD}$ value, pluviation method was used, while a needle vibrator was used for compacting the sand at $80 \% \mathrm{RD}$ value.

Total 12 set of experiments were performed as indicated in table 2. In addition to these, a few more experiments were performed to check the reproducibility of the test results, and results of the additional test results were almost similar. One set of experimental set-up and procedure is detailed here.

For the tests, for $30 \mathrm{~mm}$ diameter model test pile, a sand bed of about $300 \mathrm{~mm}$ was prepared as described earlier. After levelling the sand surface with a straight edge, the model pile was suspended centrally and vertically in the container. The pile was fitted to the reaction frame and proving ring arrangement. Using the methodology of [24], sand was continuously poured and was resumed after pile installation until the specified height of the sand in the tank was reached. Although the method of pile installation used

Table 2. Test arrangement and conditions.

\begin{tabular}{lcccc}
\hline $\begin{array}{l}\text { Test } \\
\text { set }\end{array}$ & $\begin{array}{c}\text { Diameter of } \\
\text { pile }\end{array} D_{\mathrm{p}}(\mathrm{mm})$ & $\begin{array}{c}\text { Unit weight of } \\
\text { sand }\left(\mathrm{kN} / \mathrm{m}^{3}\right)\end{array}$ & $\begin{array}{c}\text { Distance } \\
x(\mathrm{~mm})\end{array}$ & Tunnel \\
\hline A & 30 & 15.12 & 30 & Without \\
B & 30 & 15.12 & 30 & With \\
C & 30 & 17.87 & 30 & Without \\
D & 30 & 17.87 & 30 & With \\
E & 34 & 15.12 & 30 & Without \\
F & 34 & 15.12 & 30 & With \\
G & 34 & 17.87 & 30 & Without \\
H & 34 & 17.87 & 30 & With \\
I & 38 & 15.12 & 30 & Without \\
J & 38 & 15.12 & 30 & With \\
K & 38 & 17.87 & 30 & Without \\
L & 38 & 17.87 & 30 & With \\
\hline
\end{tabular}




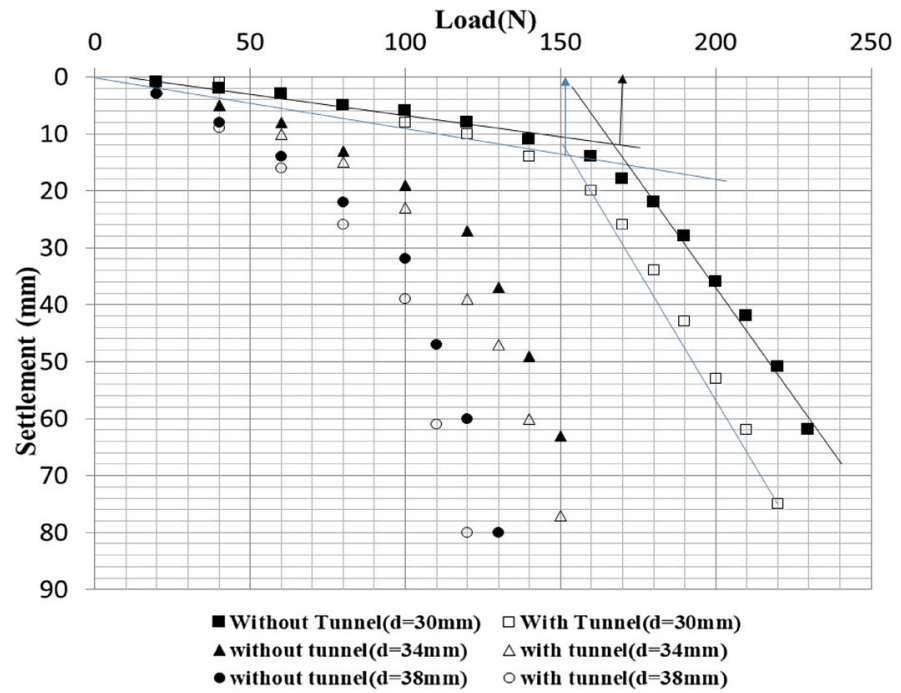

Figure 3. Load-settlement response of experimental study with and without tunnel (medium sand @ 50\% RD).

is not used in practice, it was selected to eliminate inconsistencies produced by driving or pushing the pile into the soil, which may affect the density of the tested sand.

Pile was embedded up to $300 \mathrm{~mm}$ length to investigate its ultimate bearing capacity in the absence of tunnel. Gradual load was applied on the pile using the hydraulic jack and for each load increment, settlement of pile was measured from the scale marked on the pile shaft. The sand was placed at a density of $15.12 \mathrm{kN} / \mathrm{m}^{3}$ and test was performed without utility tunnel. In test $\mathrm{B}$, before applying load on the pile, utility tunnel modelled with PVC pipe was placed adjacent to the pile at a horizontal distance of $30 \mathrm{~mm}$ and load settlement response was obtained. In a similar manner, all others tests have been performed for 34 and $38 \mathrm{~mm}$ diameter pile size. Further, all these sets of tests were repeated for increased density of the sand $(17.87 \mathrm{kN} /$ $\mathrm{m}^{3}$ ). At the end of each test, sand was removed and replaced as per the afore-mentioned procedure to ensure homogeneity and required density.

\section{Results and discussion}

The experimental study results are presented by load-settlement curve. The ultimate load carrying capacity is determined from curves by the tangent method. Load-settlement responses for medium and dense sand are shown, respectively, in figures 3 and 4 .

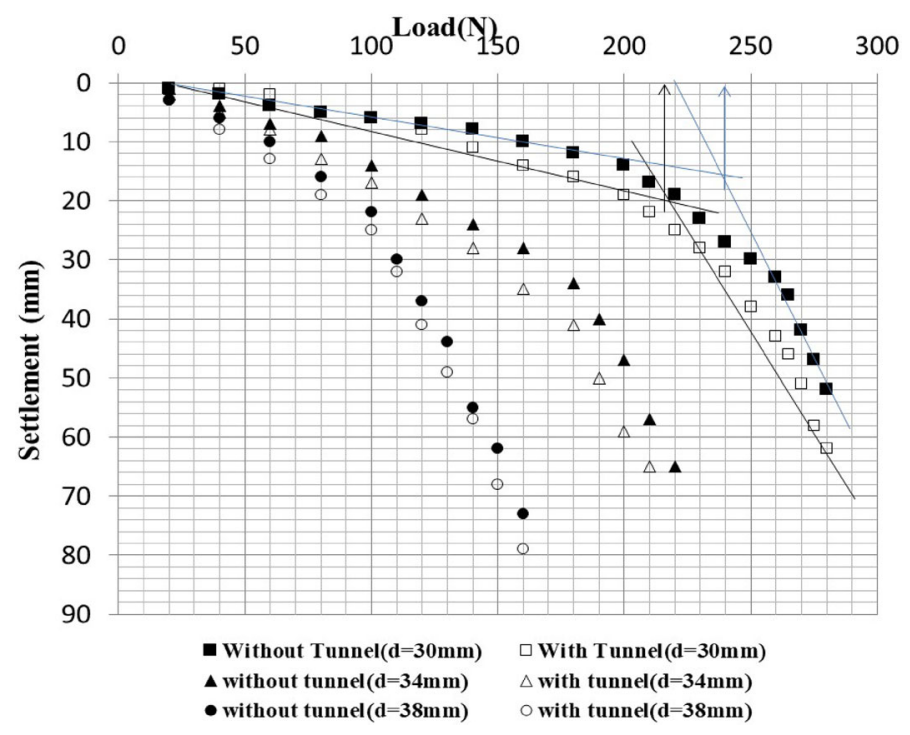

Figure 4. Load-settlement response of experimental study with and without tunnel (dense sand @ 80\% RD). 
Table 3. Sand parameters considered in the numerical analysis.

\begin{tabular}{lc}
\hline Description & Parameters \\
\hline Material type & Dry sand \\
Material model & Mohr-Coulomb \\
Material behaviour & Drained \\
Unsaturated unit weight & $15.12 \mathrm{kN} / \mathrm{m}^{3}$ (for medium sand) \\
& $17.87 \mathrm{kN} / \mathrm{m}^{3}$ (for dense sand) \\
Poisson's ratio $\mu$ & 0.35 (assumed) \\
Angle of internal friction & $25.5^{\circ}$ (for medium sand) \\
$\phi^{\circ}$ & $31.1^{\circ}$ (for dense sand) \\
Effective cohesion $c$ & $0.1 \mathrm{kN} / \mathrm{m}^{2}$ (to avoid numerical \\
& instability) \\
Elastic modulus of sand & $20.81 \mathrm{MPa}$ (for medium sand) \\
$E_{\mathrm{s}}$ & $31.21 \mathrm{MPa}$ (for dense sand) \\
\hline
\end{tabular}

The arrows in the curve indicate the ultimate bearing capacity of pile of diameter $30 \mathrm{~mm}$ with and without tunnel adjacent to it, and they show reduction in pile capacity when tunnel is lying adjacent to it. For case A, this reduction is approximately $11 \%$ in case of medium sand and $8 \%$ in case of dense sand. This $\%$ reduction in capacity increases with increase in pile diameter, tunnel being at the same location. This is because zone of influence of pile increases in proportion to its diameter. This reduction has been observed in the range of $11-16 \%$ in case of medium and $8-14 \%$ for dense sand.

\subsection{Numerical analysis}

Numerical analysis of the experimental work has been performed using commercially available finite-element tool Plaxis 2D. Fifteen-noded triangle elements have been used to discretize the physical domain, and the model and interface elements are defined by five pairs of nodes. The vertical and horizontal boundaries are kept far away from the tunnel-pile system to ensure that there is no boundary effect. The size of the numerical model is kept the same as that used during model study.

The input parameters (material properties) of in situ soil are given in table 3. They are taken in such a way they represent dry cohesionless sand and ensure Mohr-Coulomb behaviour. Further, angle of internal friction for medium and high density sand has been used as suggested in Bowel (1996) [25]. A linear elastic model was used for pile and various other parameters used in the numerical modelling are listed in table 4 . The bored tunnel option is used to represent utility tunnel, and plate element is used to represent tunnel lining. The tunnel is assumed to be elastic and its properties are provided in table 5.

Step-by-step procedure for the numerical analysis involves defining the problem geometry, assigning the material properties, boundary conditions and application of the load at the pile. After setting these initial conditions, the finite-element calculations are performed and the
Table 4. Pile parameters assumed in the numerical analysis (steel pipe).

\begin{tabular}{lc}
\hline Description & Parameters \\
\hline Material model & Linear elastic \\
Material behaviour & Elastic \\
Elastic modulus of pipe $E_{\mathrm{p}}$ & $2 \times 10^{8} \mathrm{kPa}$ \\
\hline
\end{tabular}

Table 5. Tunnel lining parameters assumed in the numerical analysis (PVC).

\begin{tabular}{lc}
\hline Description & Parameters \\
\hline Material type & Elastic \\
EA & $21,980 \mathrm{kN} / \mathrm{m}$ \\
EI & $2.917 \mathrm{kN} / \mathrm{m}^{2} / \mathrm{m}$
\end{tabular}

settlement is recorded for the corresponding applied load. The steps are repeated for the incremental loads and corresponding displacements are recorded. In this way, the load-settlement curve is obtained for both without and with utility tunnel cases, which is used to estimate the effect of already existing utility tunnel on the pile capacity. Figure 5 shows the numerical model generated for further analysis.

The ultimate bearing capacity was determined through the load-settlement curve, which was drawn from the results obtained from numerical analysis. Reduction in pile capacity was also calculated for the case when the tunnel was lying adjacent to pile. Table 6 compares the estimated $\%$ reduction in the pile capacity determined through experimental work and numerical analysis for different pile diameters. This $\%$ reduction has been observed in the range of $11-14 \%$ for medium sand and $8-12 \%$ in case of dense sand.

It can be noted that the results of model study are quite comparable to the corresponding results obtained from the numerical analysis. The maximum variation of experimental and numerical results was observed as $15 \%$ for $38 \mathrm{~mm}$ diameter pile. As the variation of result is within $15 \%$ for all the observed cases, it can be concluded that the experimental modelling is in agreement with the numerical analysis. Hence, the work has been extended further and the effect of parametric variation of pile dimensions and soil properties has been studied. For practical application of the work, diameter of the pile, angle of friction and elastic modulus of soil have been varied.

\section{Parametric study}

In the parametric study, single pile responses are studied, numerically, in the form of load-settlement curve, and the pile capacity is estimated for the two cases, i.e., (i) without an existing tunnel and (ii) with existing tunnel, as shown in figure 6. Parametric study is performed by varying the diameter 


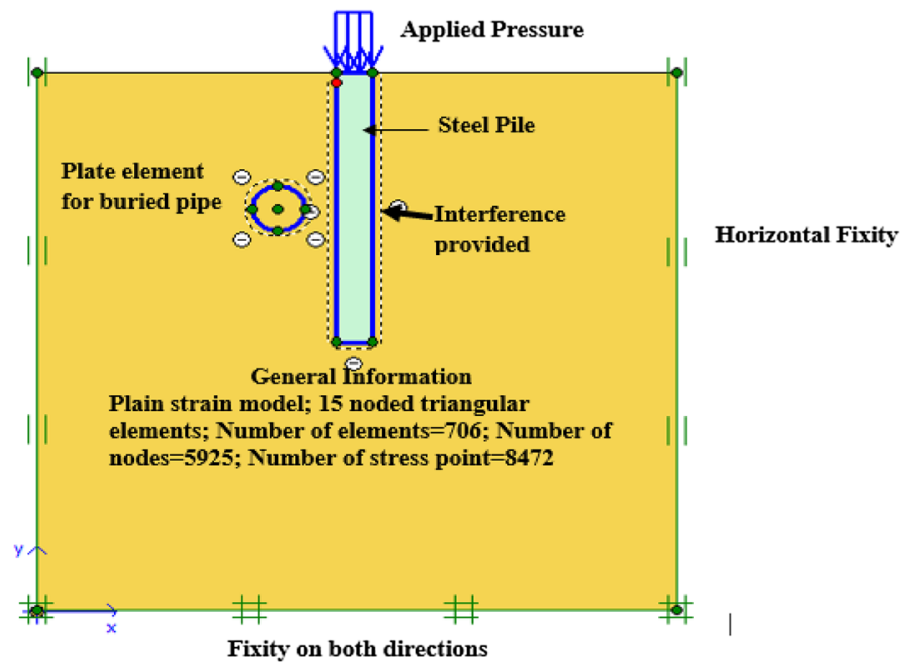

Figure 5. Numerical model using PLAXIS 2D software and properties of numerical model.

Table 6. Percentage reduction in pile capacity.

\begin{tabular}{|c|c|c|c|c|c|c|}
\hline \multirow{2}{*}{$\begin{array}{l}D(\mathrm{~mm}) \\
\text { Soil type }\end{array}$} & \multicolumn{2}{|r|}{30} & \multicolumn{2}{|r|}{34} & \multicolumn{2}{|r|}{38} \\
\hline & FEM analysis & Experimental analysis & FEM analysis & Experimental analysis & FEM analysis & Experimental analysis \\
\hline Medium sand & 10.42 & 11.38 & 11.76 & 14.08 & 13.93 & 15.0 \\
\hline Dense sand & 7.14 & 8.36 & 9.57 & 11.38 & 12.1 & 14.08 \\
\hline
\end{tabular}

of pile $\left(d_{\mathrm{p}}=0.5,1.0,1.5,2.0 \mathrm{~m}\right)$, strength parameters $(c=0$ and $\left.\phi=25^{\circ}, 30^{\circ}, 35^{\circ}, 40^{\circ}\right)$ and stiffness properties of in situ soil with respect to pile material $\left(E_{\mathrm{p}} / E_{\mathrm{s}}=3000,6000,9000\right.$, 12000 ), where $E_{\mathrm{p}}$ is elastic modulus of pile material (considered as steel pile) and $E_{\mathrm{s}}$ is the elastic modulus of soil. The unit weight of the in situ soil was also varied from 17.0 to $18.5 \mathrm{kN} /$ $\mathrm{m}^{3}$, in an increment of 0.5 , to ensure a correlation between unit weight and the four cases of varying strength and stiffness parameters. The length of the pile is fixed as $10 \mathrm{~m}$ and the diameter of the utility tunnel as $3.0 \mathrm{~m}$. The centre of the tunnel is modelled at a depth of $5 \mathrm{~m}$ from the ground level and the pile is placed at a horizontal distance of $0.5 \mathrm{~m}$ from the periphery of the utility tunnel. Totally 64 cases have been studied and divided into four major groups based on different values of

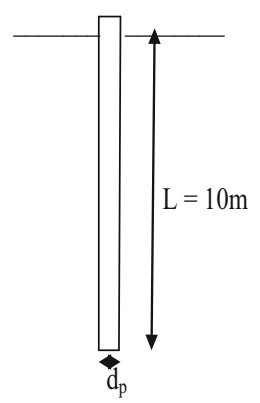

Analysis I: Without tunnel

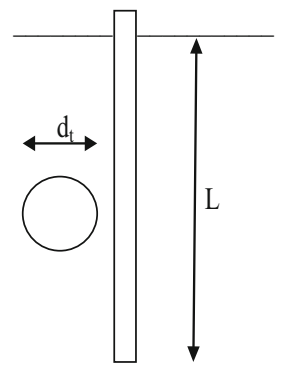

Analysis II: With tunnel angle of friction $\phi$ and unit weight of soil. In the first group the pile is embedded in sand with $\phi=25^{\circ}$ and unit weight $=17$ $\mathrm{kN} / \mathrm{m}^{3}$. For different $E_{\mathrm{p}} / E_{\text {soil }}$ ratios, variation of pile settlement with applied axial load is drawn for different pile sizes. A total of 16 cases have been studied in this group and similarly each group has totally 16 cases for different values of $\phi$ and unit weight of sand, i.e. $\phi=30^{\circ}, 35^{\circ}, 40^{\circ}$ and unit weight of 17.5 , 18 and $18.5 \mathrm{kN} / \mathrm{m}^{3}$. The load-settlement curves have been

Table 7. Steel pile parameters considered in the numerical analysis.

\begin{tabular}{lc}
\hline Description & Parameters \\
\hline Material model & Linear elastic \\
Material behaviour & Elastic \\
Elastic modulus of pile & $2 \times 10^{8} \mathrm{kPa}$
\end{tabular}

Table 8. Tunnel lining parameters considered in the numerical analysis (steel pipe).

\begin{tabular}{lc}
\hline Description & Parameters \\
\hline Material type & Elastic \\
EA & $1.4 \times 10^{7} \mathrm{kN} / \mathrm{m}$ \\
EI & $1.43 \times 10^{5} \mathrm{kN} / \mathrm{m}^{2} / \mathrm{m}$ \\
$D$ & 0.35 \\
$W$ & 8.4
\end{tabular}

Figure 6. Geometry of the problem for numerical analysis. 

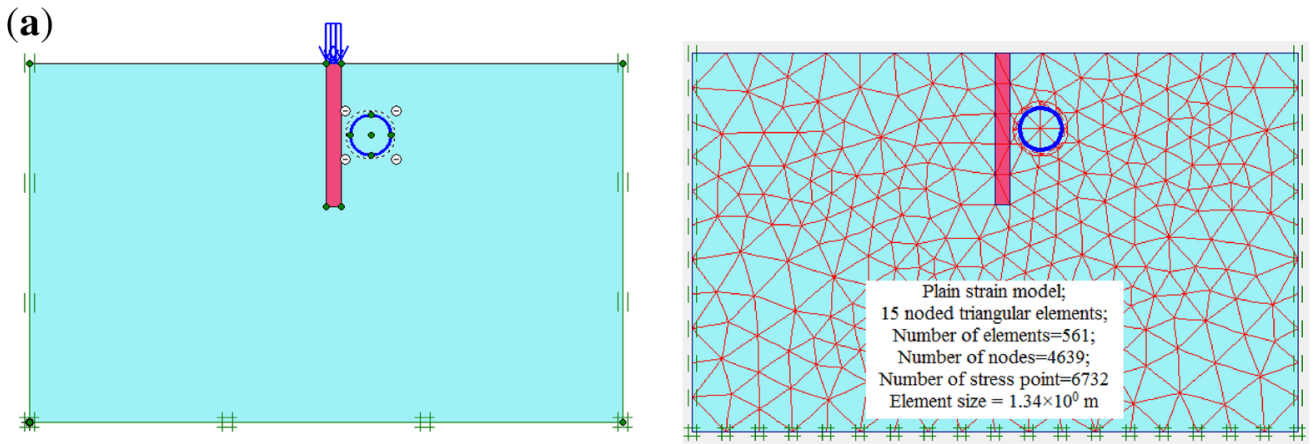

(b)

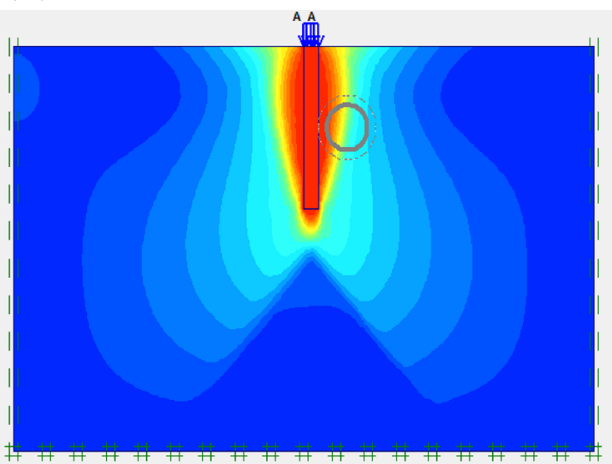

(c)

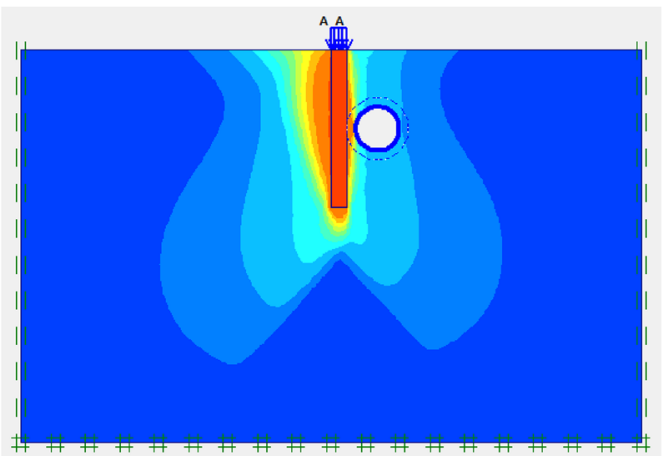

Figure 7. (a) Numerical model with generated mesh for the case with $\phi=25^{\circ}$ and unit weight of $17 \mathrm{kN} / \mathrm{m}^{3}$. (b) Deformation pattern (without tunnel).(c) Deformation pattern (with tunnel).
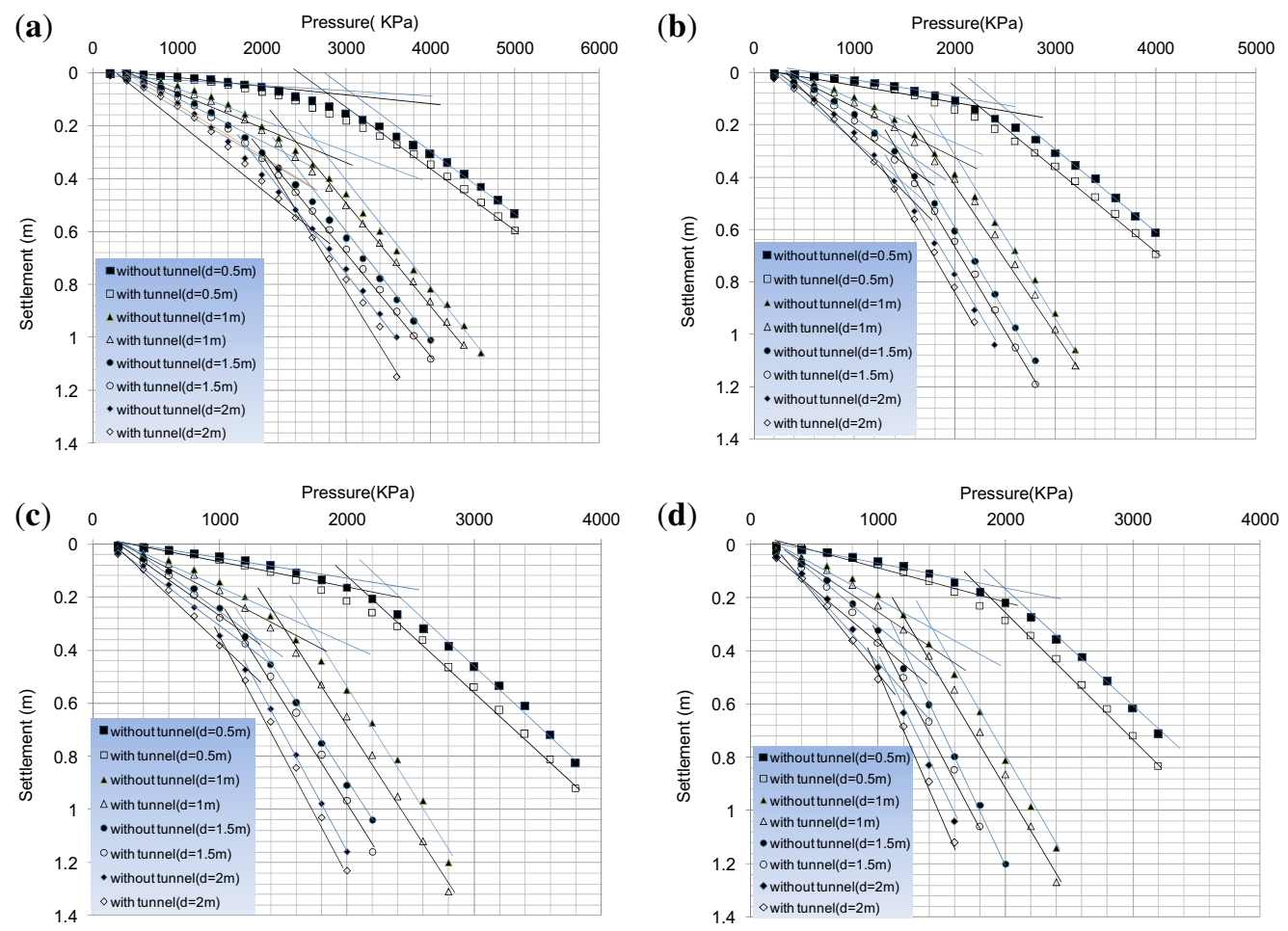

Figure 8. (a) Load-settlement response with and without tunnel for $0.5,1,1.5$ and $2 \mathrm{~m}$ diameter pile obtained for $E_{\mathrm{p}} / E_{\mathrm{s}}=3000$. (b) Load-settlement response with and without tunnel for $0.5,1,1.5$ and $2 \mathrm{~m}$ diameter pile obtained for $E_{\mathrm{p}} / E_{\mathrm{s}}=6000$. (c) Loadsettlement response with and without tunnel for $0.5,1,1.5$ and $2 \mathrm{~m}$ diameter pile obtained for $E_{\mathrm{p}} / E_{\mathrm{s}}=9000$. (d) Load-settlement response with and without tunnel for $0.5,1,1.5$ and $2 \mathrm{~m}$ diameter pile obtained for $E_{\mathrm{p}} / E_{\mathrm{s}}=12000$. 
(a)

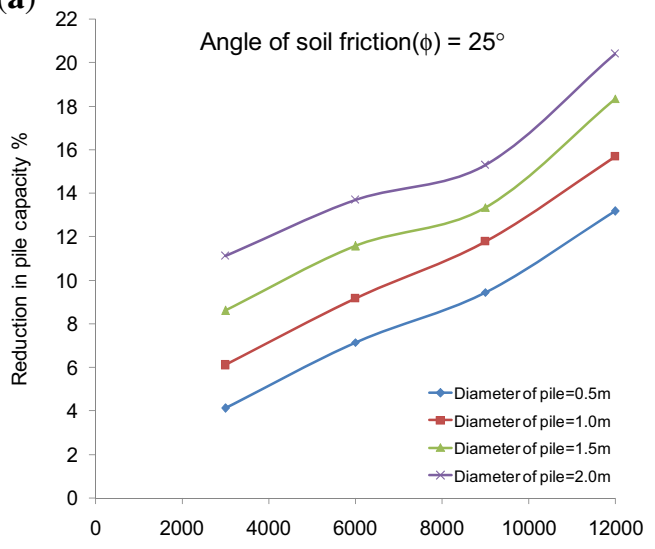

(c)

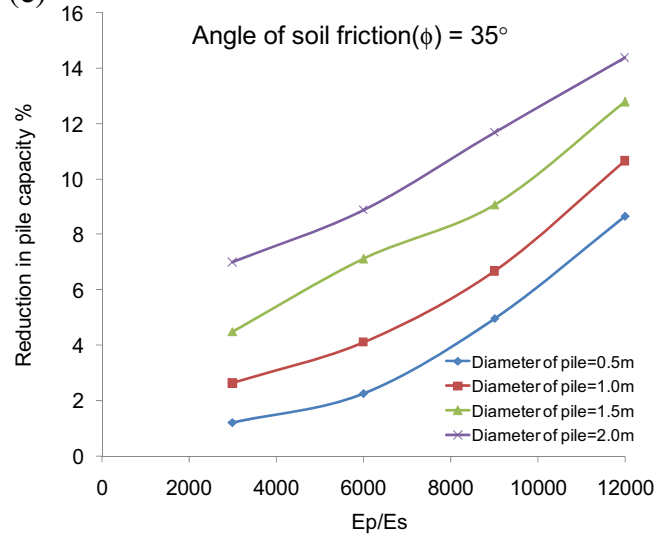

(b)

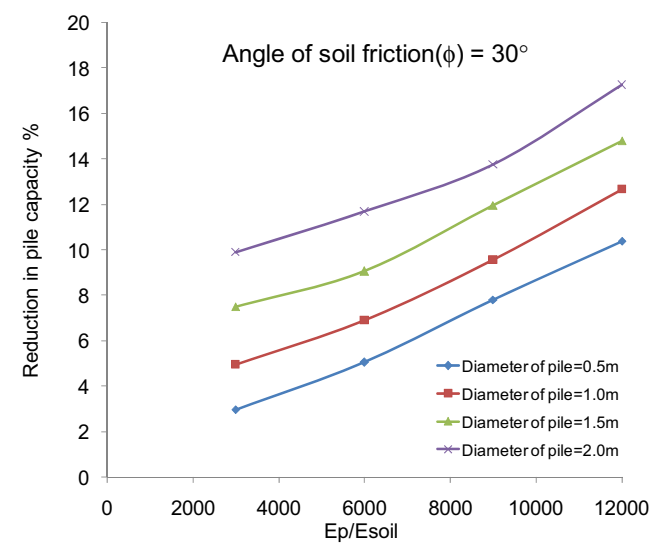

(d)

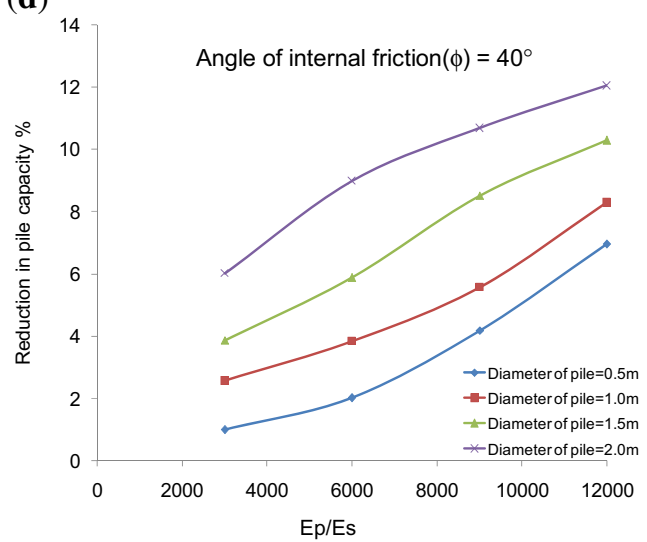

Figure 9. (a) Reduction in pile capacity for angle of internal friction of soil $\left(\phi=25^{\circ}\right)$. (b) Reduction in pile capacity for angle of internal friction of soil $\left(\phi=30^{\circ}\right)$. (c) Reduction in pile capacity for angle of internal friction of soil $\left(\phi=35^{\circ}\right)$. (d) Reduction in pile capacity for angle of internal friction of soil $\left(\phi=40^{\circ}\right)$.

drawn for each major group considering the presence of tunnel as well as absence of tunnel.

The modelled pile is assumed to be a steel pile and the input parameters are listed in table 7 . For assumed $E_{\mathrm{p}} / E_{\mathrm{s}}$ value of $3000,6000,9000$ and 12000 the corresponding modulus of elasticity of soil $E_{\mathrm{s}}$ is computed as $66.674,33.33,22.22$ and $16.67 \mathrm{MPa}$, respectively; accordingly, the unit weights of soil used are $17,17.5,18$ and $18.5 \mathrm{kN} / \mathrm{m}^{3}$ and angles of friction are $25^{\circ}, 30^{\circ}, 35^{\circ}$ and $40^{\circ}$, respectively. These assumptions are reasonably acceptable considering the range of input soil parameters for cohesionless dry sand [2]. Tunnel lining is modelled as plate elements and the input parameters of plate element are provided in table 8.

Step-by-step procedure as detailed in section 3.1 is followed for the numerical analysis and the load-settlement curve is obtained, which is used to estimate the capacity of the pile. As the bottom of the pile is not restrained, it is assumed that the pile behaves like a friction pile and the contribution from the pile tip is negligible. In a comparative study, where the pile capacity is compared without and with existence of the tunnel, the contribution from the pile tip automatically gets cancelled and the assumption of friction pile is justified. The results of the parametric study are reported in terms of percentage reduction in the pile capacity due to the presence of tunnel after comparing the load-settlement response for the two cases.

Figure 7(a) shows numerical model and finite-element mesh generated for parametric study. Figure 7(b) and (c) shows the stress contours for both the cases (without and with tunnel). It can be observed here that the presence of tunnel changes the stress pattern as it lies within influence zone of the pile. Further, as the soil between the pile and the utility tunnel gets overstressed, the pile capacity reduces.

Figure 8(a)-(d) shows typical numerical analysis results of for the first group $\left(\phi=25^{\circ}\right.$, unit weight of $\left.17 \mathrm{kN} / \mathrm{m}^{3}\right)$ without and with the tunnel in the vicinity of the single installed pile.

It can be observed that with increase in diameter of the pile, $\%$ reduction in the pile capacity increases. It may be due to increase in the zone of influence with diameter. Moreover, larger area of zone of influence is intercepted by the existing utility tunnel and hence capacity further reduces. It is also noteworthy that percent reduction in the pile capacity increases with the $E_{\mathrm{p}} / E_{\mathrm{s}}$ ratio, as the surrounding soil becomes relatively less stiffer as compared with the pile. The reduction in 
the pile capacity for first group ranges from $5 \%$ to $20 \%$ and it follows a certain trend.

FEM analysis shows that the presence of utility tunnel increases the zone of influence and decreases pile capacity; therefore reduction in pile capacity in the vicinity of utility tunnel has been presented separately with graphs (figure $9 \mathrm{a}-\mathrm{d}$ ).

It can be noted that the presence of utility tunnel increases the intercepted area and thus results in reduction in pile capacity. The $\%$ reduction in the pile capacity increases with diameter of the pile and it may be due to increase in the zone of influence with pile diameter. More area of influence is intercepted by the existing utility tunnel. Also, with increase in the $E_{\mathrm{p}} / E_{\mathrm{s}}$ ratio, there is an increase in the $\%$ reduction in the pile capacity. As $E_{\mathrm{p}} / E_{\mathrm{s}}$ ratio increases, the stiffness of the surrounding soil decreases with respect to the stiffness of the pile material.

\section{Conclusion}

The responses of a single pile lying in the vicinity of the existing tunnel has been analysed through experimental work and validated using numerical analysis approach. Parametric studies have been performed to increase the practical application of the present work. Following important conclusions are drawn from the present study:

1. Depending on the geotechnical properties of the in situ soil and relative stiffness of the pipe-soil materials, it is noted that presence of existing utility tunnel affects the bearing capacity of the pile when the boundary of the utility tunnel exists in the range of 3-5 times the diameter of the pile measured from the pile perimeter.

2. Reduction in the pile capacity ranges from $5 \%$ to $20 \%$ depending on the pipe material, geotechnical properties of in situ soil and relative stiffness of pile with the surrounding soil. Although proposed pile reduction charts can be used for the preliminary estimation of the $\%$ reduction in the pile capacity, a detailed numerical analysis is must for addressing the site-specific issues.

\section{Acknowledgement}

The authors thnakthe Department of Science and Technology, Government of India, for financial support vide reference no. WOS-A/ET-1006/2015 under Women Scientist Scheme to carry out this work.

\section{References}

[1] Chen L T, Poulos H G and Loganathan N 1999 Pile responses caused by tunneling. Journal of Geotechnical and Geoenvironmental Engineering 125: 207-215
[2] Poulos H G and Deng W 2004 An investigation on tunneling induced reduction of pile geotechnical capacity. In: Proceedings of the 9th Australia-New Zealand Conference on Geomechanics, vol. 1, New Zealand Geotechnical Society and Australian Geomechanics Society, pp. 116-122

[3] Jacobsz S W 2002 The effect of tunneling on piled foundations. PhD Thesis, University of Cambridge, Cambridge

[4] Jacobsz S W, Standing J R, Mair R J, Hagiwara T and Sugiyama T 2004 Centrifuge modelling of tunnelling near driven piles. Soils and Foundation 44: 49-56

[5] Loganathan N, Poulos H G and Xu K J 2001 Ground and pile-group responses due to tunneling. Soils and Foundation 41: $57-67$

[6] Poulos H G 2006 Pile settlement zones above and around tunnelling operations. Australian Geomechanics 41: $81-90$

[7] Maosong H, Zhang C and Li Z 2009 A simplified analysis method for the influence of tunneling on grouped piles. Tunnelling and Underground Space Technology 24: 410-422

[8] Marshai A 2012 Tunnel-pile interaction analysis using cavity expansion methods. Journal of Geotechnical and Geoenvironmental Engineering 138: 1237-1246

[9] Marshai A M and Haji T 2015 An analytical study of tunnelpile interaction. Tunnelling and Underground Space Technology 45: 43-51

[10] Franza A, Marshai A M, Haji T, Abdelatif A O and Carbonari S 2017 A simplified elastic analysis of tunnel-piled structure interaction. Tunnelling and Underground Space Technology 61: 104-121

[11] Boonsiri I and Takemura J 2015 A centrifuge model study on pile group response to adjacent tunneling in sand. Journal of JSCE 3: 1-18

[12] Meguid M A and Mattar J 2009 An investigation of tunnel-soil-pile interaction in cohesive soils. Journal of Geotechnical and Geoenvironmental Engineering 135(7): 973-979

[13] Mroueh H and Shahrour I 2002 Three-dimensional finite element analysis of the interaction between tunneling and pile foundations. International Journal of Numerical and Analytical Methods in Geomechanics 26: 217-230

[14] Dias T and Bezuijen A 2015 Data analysis of pile-tunnel interaction. Journal of Geotechnical and Geoenvironmental Engineering 141: 251-255

[15] Soomro M A, Hong Y, Ng C W W, Lu H and Peng S 2015 Load transfer mechanism in pile group due to single tunnel advancement in stiff clay. Tunnelling and Underground Space Technology 45: 63-72

[16] Soomro M A, Ng C W W, Liu K and Memon N A 2017 Pile responses to side-by-side twin tunneling in stiff clay: effects of different tunnel depths relative to pile. Computers and Geotechnics 84: 101-116

[17] Al-Omari R R, Al-Azzawi A A and Kadhim A 2016 Behavior of piled rafts overlying a tunnel in sandy soil. Geomechanics and Engineering 10: 599-615

[18] Schroeder F C, Potts D M and Addenbrooke T I 2004 The influence of pile group loading on existing tunnels. Geotechnique 54: 351-362

[19] Yao J, Taylor R N and McNamara A M 2009 The effects of loaded bored piles on existing tunnels. In: Proceedings of the 6th International Symposium on Geotechnical Aspects of 
Underground Construction in Soft Ground, Balkema, Leiden, Netherlands, pp. 735-741

[20] Vu N M, Wout Broere W and Bosch J W 2017 Structural analysis for shallow tunnels in soft soils. International Journal of Geomechanics 17: 33-84

[21] Srivastava A and Malhotra M 2017 Influence of existing nearby tunnel on frictional resistance of single pile capacity in cohesionless soil. In: Proceedings of the 19th International Conference on Soil Mechanics and Geotechnical Engineering, Seoul, South Korea
[22] Robinsky E I and Morrison C F 1964 Sand displacement and compaction around model friction piles. Canadian Geotechnical Journal 1: 81-93

[23] Bolton M D 1999 Centrifuge cone penetration tests in sand. Geotechnique 49: 543-552

[24] Al Mhaidib A I 2006 Experimental investigation of the behaviour of pile groups in sand under different loading rates. Geotechnical and Geological Engineering 24: 889-902

[25] Bowel J E 1996 Foundation analysis and design. New York: McGraw Hill 